\title{
Front Matter: Volume 10258
}

, "Front Matter: Volume 10258," Proc. SPIE 10258, Machine Vision Systems Integration: A Critical Review, 1025801 (1 September 1991); doi:

$10.1117 / 12.2284093$

SPIE. Event: Critical Reviews, 1991, San Jose, CA, United States 


\section{Contents}

vii Preface

3 Building an infrastructure for system integration: machine vision standards

L. H. Bieman, Industrial Technology Institute; J. A. Peyton, Automated Imaging Association

20 Illumination and viewing methods for machine vision

G. T. Uber, Lockheed Missiles \& Space Co., Inc.; K. G. Harding, Industrial Technology Institute

34 Essential for success: people as part of the system

J. J. Fosdick, Fosdick and Co.

46 Shortage of system integrators

D. W. Braggins, Machine Vision Systems Consultancy (UK)

56 Case studies in machine vision integration

R. Ahlers, Rauschenberger (FRG)

63 Inspecting colored objects using gray-level vision systems

A. P. Plummer, Image Inspection Ltd. (UK)

$78 \quad$ Distributed industrial vision systems

P. Neve, Image Inspection Ltd. (UK)

93 Automated visual inspection of printed wiring boards

R. Chin, Univ. of Wisconsin/Madison; R. D. Iverson, Applied Vision Systems, Inc.

105 User interfaces for automated visual inspection systems

F. M. Waltz, 3M Co.

138 Tools for designing ind ustrial vision systems

B. G. Batchelor, Univ. of Wales College of Cardiff (UK)

176 Author Index

Machine Vision Systems Integration: A Critical Review, edited by Bruce G. Batchelor, Frederick M. Waltz, Proc. of SPIE

Vol. 10258 (Vol. CR36),1025801 - (C) (1991) 2017 SPIE · CCC code: 0277-786X/17/\$18 · doi: 10.1117/12.2284093 


\section{Preface}

Machine vision systems are being applied in a wide variety of situations and are successfully performing many different types of measurement, inspection, and control functions. However, the adoption of machine vision technology has been slower than many companies anticipated three to five years ago. In addition, there are too many anecdotes about "failures," in which machine vision systems have unfortunately not provided the desired improvement in production efficiency and/or product reliability. It is still notoriously difficult to get the first machine vision system installed in a company. Then or later, any hint of vision systems being impractical, slow, inflexible, difficult to program, or unreliable discourages skeptical managers from investing in them. It would be fallacious to attribute the sluggish market for machine vision systems to a single cause. Many contributory factors can be identified and, no doubt, each worker in this field would assess their relative importance slightly differently. It is therefore a little hazardous for the editors to offer firm opinions about this, but, forsaking caution, they will offer the following suggestions:

(1) Machine vision is potentially very versatile. In practice, it is still uncompetitive in most cases in comparison with the other options, which include inspection by human beings, improvement of the production process, and doing nothing.

(2) Machine vision is perceived by many potential customers as being merely the automation of human vision. This assertion has to be emphatically refuted. Nearly every person with normal sight regards themselves as experts in human vision. As a result, many people, both within the industry and outside, fail to understand that a machine does not see as they do. This often leads to machines being designed in an inappropriate way.

(3) Machine vision has been the subject of numerous articles in the popular commercial press, many of which have failed to point out the great importance of ensuring that the machine is specially tailored to fit the task at hand. Many articles have oversimplified the subject and thereby created false confidence, or have been the source of unwarranted discouragement. Either of these conclusions can be drawn when too little knowledge is gained.

(4) Long-established patterns of thinking have to be modified. Consider, for example, the question as to what an artifact is made of. A vision engineer might be told by a production engineer that a certain widget is made of brass. What the production engineer may well forget to say is that the widget may be lacquered or painted bright blue. To a vision system, the fact that the widget has a painted or lacquered surface is of paramount importance. As far as human or machine vision is concerned, the surface finish/covering is more important than the substrate material. Other long-established patterns of thought also require modification. It may even be necessary to redefine the inspection criteria to take account of the new method of measurement. This approach is not new; remember that metrological measurements are often defined in such a way that they can be obtained easily.

(5) Automated visual inspections machines are very often perceived as being "bolt on" devices to be fitted when all other options have been considered and eliminated. They are not often considered as forming an integral part of the manufacturing process.

(6) Lack of imagination prevents many potential applications from being realized. Most inspection machines are used to cure a problem that a production engineer has previously identified. However, there are numerous places where a vision engineer, given the chance 
to walk freely around a factory, can see a potential application. Are vision systems engineers destined to operate like firemen, waiting to act until there is a serious problem that nobody can solve?

(7) The title "Automated Visual Inspection" is almost invariably interpreted as applying to the product, only very rarely to the process. The possibility of applying machine vision systems to monitoring the manufacturing process is a new concept to many people and consequently has not yet gained full acceptance. There is a large potential market here; recall how many people are employed in industry to monitor and adjust the flow of a fluid or power, the size or color of a flame, the cone of an aerosol spray, the flow of materials/ parts along a conveyor, etc.

Lack of appreciation of the systems issues involved in the installation of a successful machine vision system is unfortunately all too common. The editors once knew a senior manager of an inspection equipment supply company who firmly believed that vision systems could be packaged, like an item of PC software, providing a plug-in board, disc, cables, and a manual. It is difficult to comprehend how anybody in that position could have been so wrong; the company is no longer trading.

A very real convergence of thinking was evident at the conference and is also visible in these pages. Without doubt, there is a growing consensus of opinion that the key problems of our subject are those relating to systems issues. The papers by Leonard $\mathrm{H}$. Biemann and James A. Peyton (p. 3), Don W. Braggins (p. 46), Frederick M. Waltz (p. 104), and Bruce G. Batchelor (p. 133) make this point and address the issue directly. Until very recently, the pivotal task for most machine vision systems designers was the provision of fast, cheap, versatile image processing hardware. The existence of a "secondary problem," relating to image acquisition, was also acknowledged, albeit reluctantly by some people. The papers just cited all make the point that there is a very large number of other equally important factors to be considered. Standards for calibrating/testing systems, interfacing, optics, and lighting are all discussed (Biemann, Peyton). There is a shortage of skilled design engineers (Braggins), and the situation will get worse if, as we all hope, the reputation of our subject becomes more firmly established, having made a major contribution to the efficiency of the manufacturing industry. Several design tools are under development to try and make the best use of the available personnel (Biemann and Peyton, Batchelor). There is a clear need to train more engineers with the appropriate skills, but there are other problems as well. Designing and building a successful machine vision system requires a special kind of mind, capable of drawing together information about the optical, mechanical, electronic, software, and mathematical components of the system. There are not many people with this ability, so we must make the best use of those that we have. Braggins also addresses the critical question as to whether systems integration represents good business. Waltz discusses graphical and other user-machine interfaces and demonstrates how important it is to have a good method of programming a vision system. In this context, programming does not necessarily mean writing $\mathrm{C}$ code. Indeed, this is the very thing we must avoid, if unskilled personnel are ever to be able to modify a machine for a new product. Batchelor suggests that Prolog might be used for analyzing natural language descriptions of the objects to be inspected, thereby circumventing the need for conventional programming.

A few years ago, one of the editors was invited, with very little notice, to make a short after-lunch speech to the assembled delegates at an international conference on machine vision systems technology. Faced with the daunting task of planning a sensible and thought-provoking talk between the departure of the soup dishes and the arrival of the 
entree, he decided to make a few remarks about the need to consider the human aspects of machine vision systems, as well as their technical design. The audience response came as a complete surprise. Suddenly, the audience was aroused, and a very lively debate followed. Many speakers developed those ill-prepared points and expressed them much more eloquently. Many people present that day indicated that they had been very pleased that the issue of the human aspects of machine vision systems had been approached. The invitation to Jerilyn Fosdick to speak to this conference followed directly from this experience. Since she does not work directly with machine vision systems, her remarks are, of necessity, of a general nature; the editors hope her paper will provoke more detailed consideration of these issues. She poses a challenge to engineers: what are we doing about the vitally important subject of integrating people and machines?

The reader should make no mistake; the editors do not support the view that image acquisition is a "secondary problem." It is of vital importance to the success of any machine vision system. Gordon T. Uber and Kevin G. Harding discuss the twin topics of illumination and viewing, and present a comprehensive bibliography.

An innovative approach to color image processing is described by A. P. Plummer, who also emphasizes the need for simple programming. This permits a person to define a range of colors that he/she wishes to associate with a given label, simply by drawing a contour around a part of an image. His colleague Peter Neve discusses distributed industrial vision systems, in which there may be a large number of image sensors. For example, one configuration that Neve describes allows up to eight image processors, each with eight sensors, to be programmed and monitored from a single desktop computer. Alternatively, eight color cameras of the type described by Plummer could be controlled in the same way. These two papers demonstrate that there is still a great deal of innovation being exercised in the development of new electronic hardware for vision systems.

It is difficult to obtain a representative overview of applications studies in a set of papers like these. The editors are pleased, therefore, to be able to include papers from two very experienced sources, who describe quite different approaches to machine vision systems design. Rolf-Jürgen Ahlers considers a variety of topics, in the search for what might be called a "general purpose" machine vision system. On the other hand, Roland T. Chin and Rolf $\mathrm{D}$. Iverson discuss one very demanding problem, namely that of examining printed circuit boards. Again, the systems considerations stand out as being of the utmost importance. This lesson is all the more memorable when one considers that Iverson was instrumental in building an inspection machine that operates at an impressive speed, estimated as being in excess of 2000 MIPS.

What has surprised even the editors, who invited all of these contributions, is the remarkable degree of unity shown by these papers. In this subject there is little contention, but there is a remarkable and growing amount of coherence of opinion. We are seeing a far greater understanding of the real nature of the problem than we had just a few years ago. The problem is not simply manipulating more bits per second.

We wish to thank our friends and colleagues who have made this volume possible. We are proud to be associated with their fine work.

Bruce G. Batchelor

University of Wales College of Cardiff (UK)

Frederick Waltz 3M Company 